\title{
TT-232: An Anti-tumour and Anti-inflammatory Peptide Therapeutic in Clinical Development
}

\author{
György Kéri, ${ }^{1,2,5}$ Richard Schwab, ${ }^{2}$ Orsolya Szokolóczi, ${ }^{2,1}$ Tamás Szüts, ${ }^{3}$ and János Szolcsányi ${ }^{4}$
}

(Accepted September 9, 2004)

TT-232 is a structural derivative of the peptide hormone somatostatin with selective antiproliferative and anti-inflammatory properties. It has a strong anti-tumour activity both in vitro and in vivo on a wide range of tumour models and induces apoptosis. Its anti-tumour activity is mediated through the SSTR1 receptor and by the tumour specific isoform of pyruvate kinase. TT-232 has been shown to be a potent neurogenic inflammation inhibitory, anti-inflammatory and analgesic agent with a broader spectrum than presently available antiinflammatory/analgesic drugs. In animal models it is effective against neurogenic inflammation and blocks neuropathic hyperalgesia where COX-1 or COX-2 inhibitors (e.g. diclofenac or meloxicam) proved ineffective. TT-232 has passed phase I clinical trials without toxicity and significant side effects. Human phase II efficacy studies are ongoing in melanoma indication. Two more oncological indications and phase II clinical trials in inflammatory diseases, including rheumatoid arthritis and burn injuries are in preparation. This compound has the perspective to become the first drug in molecularly targeted therapy of inflammation where a combined effect of anti-inflammatory, analgesic and neurogenic inflammation inhibiting activity can be achieved.

KEY WORDS: TT-232; somatostatin analogue; anti-tumour activity; neurogenic inflammation; antiinflammatory activity; analgesic activity; clinical development.

\section{INTRODUCTION}

TT-232 (DPhe-Cys-Tyr-DTrp-Lys-Cys-Thr- $\mathrm{NH}_{2}$ ) is a structural analogue of somatostatin, an endogenous hormone with significant anti-proliferative,

\footnotetext{
${ }^{1}$ Peptide Biochemistry Research Group of Hungarian Academy of Sciences in the Department of Medical Chemistry, Molecular Biology and Pathobiochemistry, Semmelweis University, Budapest, Hungary.

2 Rational Drug Design Laboratory, Cooperative Research Center, Semmelweis University Medical School, Budapest, Hungary.

${ }^{3}$ Biostatin Research and Development Ltd., Budapest, Hungary.

${ }^{4}$ Department of Pharmacology, Faculty of Medicine, University of Pécs, Hungary.

${ }^{5}$ Correspondence should be addressed to: György Kéri Department of Pharmacology, Faculty of Medicine, University of Pécs, Hungary Tel: 361-275-2605/4092; Fax: 361-266-7480; e-mail: Keri@vichem.hu
}

anti-inflammatory and neurogenic inflammation inhibitory activity (Keri et al. 1993a, b; Helyes et al. 2000, 2004). In contrast to the parent hormone and its 'traditional' analogues, this compound has strong and selective anti-proliferative potential without

Abbreviations: ADME, absorption, distribution, metabolism, excretion; ALD, approximate lethal dose; AUD, area under the data; $\mathrm{AUD}_{\mathrm{e}}$, area under the data extrapolated to infinity; $\mathrm{BC}$, breast cancer; CLL, chronic lymphoid leukaemia; $\mathrm{Cl}_{\text {tot }}$, total clearance; CNS, central nervous system; COX, cyclooxigenase; DTIC, dacarbazine; GABA, gamma-aminobutyric acid; GLP, good laboratory practice; Gly, glycine; i.m., intramuscular; i.v., intravenous; LAA, lipo-amino acid; $\mathrm{LD}_{50}$, lethal dose $50 \%$; $\mathrm{LS}$, liposaccharide; MM, malignant melanoma; MRT, mean residence time; NOAEL, no observed adverse effect level; s.c., subcutaneous; SAA, sugar amino acid; SSTR1, somatostatin receptor type-1; SSTR2, somatostatin receptor type-2; SSTR4, somatostatin receptor type-4; SSTR5, somatostatin receptor type-5; $\mathrm{t}_{1 / 2}$, terminal elimination half-life; ThR, threonine; Trp, tryptophan. 
the wide-ranging endocrine side-effects, including inhibition of insulin secretion provoking diabetes. The molecule has been shown to have unique conformational characteristics (Jaspers et al. 1994; Simon et al. 2004), selective binding properties to the 1st and 4th subtypes of somatostatin receptors (SSTR1 and 4, Jing et al. and Patel unpublished results) and to the intracellular receptor: pyruvate kinase M2 (Stetak et al. 2001, 2004). No presently marketed drug or drug-candidate in clinical trials has a comparable molecular mechanism and efficacy profile on these new pharmaceutical drug-targets in the therapy of inflammation.

Somatostatin and its analogues have attracted intense attention in drug development pipelines and reached clinical application in the 1990s. The parent compound, Somatostatin is a naturally occurring tetradecapeptide hormone produced mostly by the hypothalamus and the pancreas. However, it is widely expressed in other parts of the central nervous system (Gamse et al. 1981) and the peripheral tissues as well in its 14 and 28 amino acid-containing forms (Patel et al. 1995; ten Bokum et al. 2000). It is a general inhibitor of endocrine signalling antagonizing the release of several pituitary and intestinal factors that are involved in the regulation of cellular functions including proliferation, motility and secretion. Several of these factors are involved in the regulation of tumour cell proliferation and in inflammatory processes. The therapeutic use of native somatostatin is limited by its broad range of effects and also by its very short ( $3 \mathrm{~min}$ ) plasma half life (ten Bokum et al. 2000). Analogues of somatostatin have already been used in clinical practice but many follow-up molecules are still in exploratory phase and under clinical development (Fig. 1). Sandostatin (octreotide DPhe-Cys-Phe-DTrp-LysThr-Cys-Thr-ol), its long-acting release formulation Sandostatin LAR and its radiolabelled form OctreoScan, Somatuline (lanreotide), NeoTect ${ }^{99 \mathrm{~m}} \mathrm{Tc}$ (depreotide) have been marketed worldwide, whereas Sanvar/Octastatin (vapreotide) have already completed phase III clinical trial on esophageal variceal bleeding. In addition, there are many other peptide and non-peptide analogues at various stages of development. LAN-7 was synthesised at the University of California, Oakland, an analogue of TT-232 in which a lanthionine bridge replaces the disulphide bridge between the two cysteines, making the peptide more stable. LAN-7 is being evaluated as a potential anti-tumour agent (Zheng et al. 1997). Similar to TT-232, LAN-7 has also been shown to have significant anti-proliferative effects on a number of human tumour cell lines, with the two compounds exhibiting similar potencies without concomitant toxicity on normal human haematopoietic progenitor cells.

Historically, development of TT-232 was started as a signal-transduction inhibitor drug candidate targeting oncological applications in 1992, while increasing evidence on the molecular pharmacology of its action along with extensive preclinical efficacy studies have put the anti-inflammatory indication also into the front line of present development efforts. The preclinical dossiers in both indications have been completed. Primary oncological disease targets were set to malignant melanoma (MM), breast cancer (BC) and chronic lymphoid leukaemia (CLL). After successful phase I clinics on healthy volunteers, the first human phase II (safety and dose-finding efficacy) trial using TT-232 as a single agent in late stage disseminated MM was completed. This confirmed predicted safety and showed promising clinical response. Add-on trials on $\mathrm{MM}$ and $\mathrm{BC}$ are in progress and under preparation, respectively.

The overall results of the numerous safety studies showed that TT-232 is a molecule of low toxicity: no accumulation, allergic or mutagenic effects were seen. The most significant feature is that TT-232 does not affect vital function or morphology of tissues as most cytotoxic agents used in the baseline treatment of inflammatory disorders (e.g. methotrexate in rheumatoid arthritis) and classical anti-cancer agents do. Minor side effects like hypotension and some local reactions after intravenous administration in peripheral vessels did not require medical attention.

TT-232 has been shown to be a potent neurogenic inflammation inhibitory, anti-inflammatory and analgesic agent with a broader spectrum than presently available anti-inflammatory/analgesic drugs. In animal models it is effective against neurogenic inflammation and blocks neuropathic hyperalgesia where COX-1 or COX-2 inhibitors (e.g. diclofenac or meloxicam) proved ineffective. Predicted indication profile of TT-232 is in line with 'disease-modifying' agents in the baseline therapy of 'autoimmune' inflammatory disorders, where classical anti-cancer agents have proven success in the past 20 years (see methotrexate, azathioprine, etc.). Acting on the peripheral sensory neurons, this molecule has a strong analgesic effect too, which proved significantly greater than that of non-steroid anti-inflammatory agents (e.g. diclofenac) and comparable to morphine in various animal models. After completed human phase I 


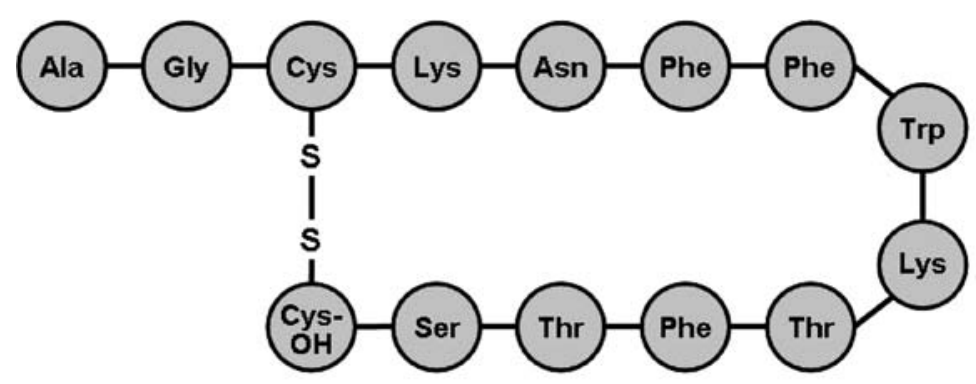

Somatostatin 14

(SRIF-14)
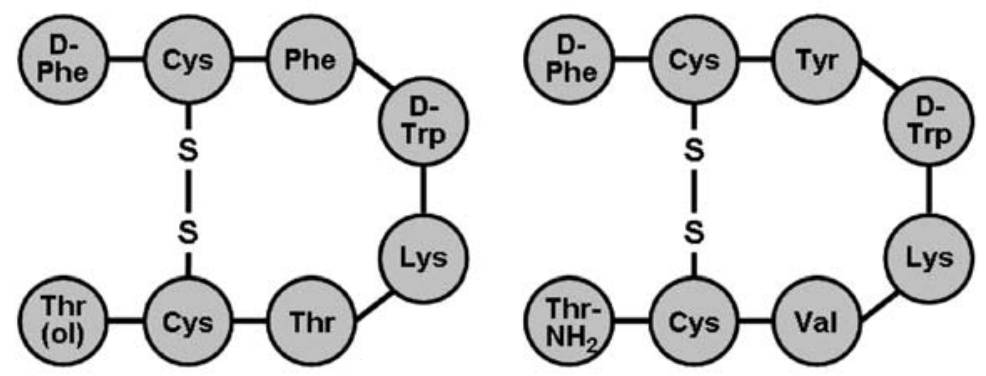

Octreotide

(SMS 201-995)

Vapreotide

(RC-160)
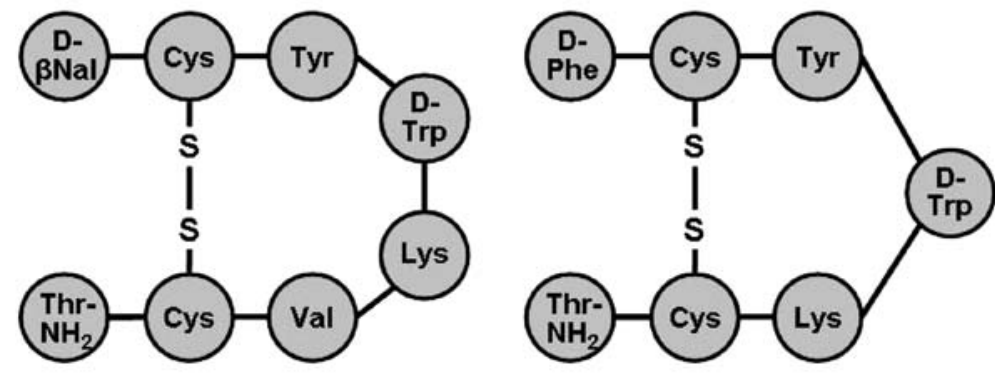

Lanreotide

TT-232

(BIM 23014)

Fig. 1. Structures of somatostatin and its analogues.

safety trials, phase II clinical studies are now planned in two of the most promising disease indications, rheumatoid arthritis and burn injuries.

\section{ANTI-NEOPLASTIC ACTIVITY OF TT-232}

It has been demonstrated, that TT-232 in 20-30 $\mu \mathrm{M}$ dose range inhibits proliferation (50-95\%) and induces apoptosis on 20 different human tumour cell lines (Keri et al. 1996, 2004; Tovari et al. 1998;
Tompa et al. 2000; Szende et al. 2003). TT-232 has been tested and found effective in 60 various human tumour cell lines by The National Cancer Institute, NIH, USA: $100 \mu \mathrm{M}$ of TT-232 had a strong antiproliferative effect on the majority of cell lines (unpublished results), while the 'traditional type' somatostatin analogues (e.g. TT-248 and octreotide) had practically no effect on the same cell lines.

TT-232 inhibited in vitro proliferation of D10, 205, LSD22, Me8, IGR3 (Siegrist et al. 1989), HBL (Siegrist et al. 1994) and SK-MEL1 human melanoma cells when tested in a dose range of $0.1-30 \mu \mathrm{g} / \mathrm{ml}$ 
TT-232 (Schwab et al. 2001): proliferation of all the cell-lines were inhibited by $100 \%$ at $30 \mu \mathrm{g} / \mathrm{ml}$, whilst the 205 cells showed even somewhat greater sensitivity, with an $\mathrm{IC}_{50}$ value of $10 \mu \mathrm{g} / \mathrm{ml}$. The anti-proliferative effect of TT-232 was also demonstrated on hepatocellular carcinoma cell lines (Diaconu et al. 1999) (including differentiated and dedifferentiated, drug sensitive and multidrug-resistant hepatomas) and on human pancreatic cancer cell lines along with a strong apoptotic response (Lee et al. 2002). In addition, treatment of M1- and WM-melanoma and K-562 leukaemia cells with $10 \mu \mathrm{g} / \mathrm{ml}$ TT-232 resulted in a distinct increase of the apoptotic index $(70,4-5$ and $60 \times$ respectively).

\section{In vivo Studies}

A great number of in vivo experiments carried out at different cancer research centers using various tumour types were conducted to define the in vivo tumour growth inhibitory properties of the molecule. Greatest efficacy was seen in the different breast, colon, melanoma, sarcoma and lymphoma tumour models (Table I), and among them, the melanoma, breast and lymphoma human xenografts were found to be the most responsive. TT-232 showed strong tumour growth inhibition at a daily dose in the low micromolar range that resulted in up to $40 \%$ clearance of the transplanted tumour and long-term survival.

Extensive studies have also targeted the relationship of the efficacy and the administration route/ duration of treatment. Comparative experiments confirmed that continuous, intravenous long-term administration (14 days or more) is associated with the best treatment response in all in vivo models studied. However, minor differences were detected between subcutaneous and intravenous administration routes that warrant further investigations.

Extrapolating these results for the human clinical application, continuous infusion therapy can be regarded as the most promising alternative in terms of ease of application and predicted efficacy. On the other hand novel formulations, similar to the long acting, slow release forms of octreotide and lanreotide are promising alternatives for future development in view of the almost equivalent efficacy and advantages associated with once-a-month injection application form.

\section{Combination Studies}

TT-232 was applied together with Etoposide and DTIC (dacarbazine) on human melanoma and lymphoma xenografts and a melanoma metastasis model in mice (Szende et al. 2003) in order to investigate the effect of TT-232 on tumour growth when applied together with known chemotherapeutic agents to mimic the combination chemotherapy in humans. In HT-18 melanoma xenografts, a combination of $1 \mathrm{mg} /$ $\mathrm{kg}$ TT-232 with 30 or $60 \mathrm{mg} / \mathrm{kg}$ DTIC (administered daily) resulted in a stronger inhibitory effect compared to TT-232 or DTIC alone. Administration of

Table I. Tumour Growth Inhibitory Effect of TT-232 at Various Routes of Administration in Experimental Tumours of Human or Animal Origin Implanted into Mice

\begin{tabular}{|c|c|c|c|c|c|c|c|c|}
\hline Tumour code & Tissue origin & Days & Route & $\begin{array}{c}\text { Dose } \\
\text { (mg/day) }\end{array}$ & $\begin{array}{c}\text { Maximum } \\
\text { inhibition }(\%)\end{array}$ & $\begin{array}{c}\text { Tx free } \\
\text { survivors }(\%)\end{array}$ & $\begin{array}{l}\text { Efficacy } \\
\text { score }\end{array}$ & References \\
\hline MDA-MB-23 & Breast $(\mathrm{H})$ & 30 & s.c. & 0.500 & 80 & 38 & ++++ & Keri et al. 1996 \\
\hline MXT & Breast $(\mathrm{H})$ & 28 & s.m.p. & 0.030 & 62 & 0 & ++ & Tejeda et al. 2003 \\
\hline MXT & Breast $(\mathrm{H})$ & 28 & i.m.p. & 0.030 & 70 & 0 & ++ & Tejeda et al. 2003 \\
\hline Colon-26 & Colon & 28 & s.m.p. & 0.030 & 57 & 0 & + & Tejeda et al. 2003 \\
\hline Colon-26 & Colon & 28 & i.m.p. & 0.030 & 60 & 0 & ++ & Tejeda et al. 2003 \\
\hline 205 & Melanoma $(\mathrm{H})$ & 14 & s.c. & 0.030 & 50 & 25 & ++++ & Schwab et al. 2001 \\
\hline B16 & Melanoma & 20 & s.c. & 1.000 & 100 & 0 & ++++ & Szende et al. 2003 \\
\hline B16 & Melanoma & 19 & s.c. & 0.750 & 50 & 0 & ++ & Keri et al. 1996 \\
\hline D-10 & Melanoma $(\mathrm{H})$ & 14 & s.m.p. & 0.150 & 50 & 13 & ++++ & Schwab et al. 2001 \\
\hline HT-18/DTIC & Melanoma (H) & 21 & s.c. & 1000 & 63 & 0 & ++ & Szende and Keri, 2003 \\
\hline S-180 & Sarcoma & 14 & s.m.p. & 0.030 & 69 & 40 & ++++ & Tejeda et al. 2000 \\
\hline S-180 & Sarcoma & 14 & i.m.p. & 0.030 & 92 & 40 & ++++ & Tejeda et al. 2000 \\
\hline p388 & Lymphoma & 28 & s.m.p. & 0.030 & 80 & 20 & +++ & Tejeda et al. 2003 \\
\hline p388 & Lymphoma & 28 & i.m.p. & 0.030 & 82 & 20 & +++ & Tejeda et al. 2003 \\
\hline HT-58/etoposide & Lymphoma $(\mathrm{H})$ & 21 & s.c. & 1.000 & 97 & 0 & ++++ & Szende et al. 2003 \\
\hline Lewis & Lung metastasis & 14 & i.v. & 0.500 & 70 & 0 & ++ & Keri et al. 1993a \\
\hline
\end{tabular}


$1 \mathrm{mg} / \mathrm{kg} /$ day TT/232 alone or in combination with 30 or $60 \mathrm{mg} / \mathrm{kg}$ DTIC resulted in a significant decrease of the number of lung metastasis in the B16 mouse melanoma muscle-lung metastasis model. However, TT-232 did not increase the effect of DTIC on the primary tumour. In HT-58 lymphoma nearly 50\% growth inhibition was achieved by daily treatment with $1 \mathrm{mg} / \mathrm{kg}$ TT-232, which corresponds to the effect of $5 \mathrm{mg} / \mathrm{kg}$ etoposide. The combination of TT-232 $(1 \mathrm{mg} / \mathrm{kg})$ and etoposide $(5 \mathrm{mg} / \mathrm{kg})$ proved to be significantly more effective than TT-232 or etoposide as a single treatment. Moreover, the very strong tumour growth inhibitory effect of $10 \mathrm{mg} / \mathrm{kg}$ etoposide could even be increased by the combination of $10 \mathrm{mg} / \mathrm{kg}$ etoposide with $1 \mathrm{mg} / \mathrm{kg}$ TT-232.

\section{Clinical Studies}

The 16 healthy volunteers involved in the human phase I/a study tolerated doses of TT-232 up to $480 \mu \mathrm{g} / \mathrm{kg}$ without significant side effects when administered in weekly increasing single doses. TT-232 was found to be non-toxic in the applied doses. In some cases local vein irritating effect was noticed (in a single case with vein occlusion), which was attributed to the high concentration of the TT-232 containing solvent. In order to avoid this side effect, the injection for infusion must be diluted at least 2.5 fold by $5 \%$ dextrose. Due to the low toxicity and the lack of serious side effects of TT-232, maximal tolerable daily dose was not reached in the study.

In the human phase I/b study TT-232 was given in $4 \mathrm{~h}$ long i.v. infusions of $480 \mu \mathrm{g} / \mathrm{kg}$ over 10 consecutive days in healthy volunteers. Plasma concentrations of TT-232 were reduced by approximately $80 \% 4 \mathrm{~h}$ after stopping the infusion and plasma concentrations were below the quantitation limit in each case after $20 \mathrm{~h}$. As minor side effects superficial vein irritation and bradycardia was observed in some cases but without medical significance. Neither any clinically relevant side effect, nor any cumulation of TT-232 in the plasma could be found in this study.

An open-label, one group human phase II/a study was carried out in patients with metastatic malignant melanoma resistant to previous therapy to assess the efficacy and safety of TT-232. Patients were treated with $4 \mathrm{~h}$ daily infusions of $480 \mu \mathrm{g} / \mathrm{kg}$ TT-232 for 7 days followed by a 7-day-wash-out period. Each patient received four cycles of the experimental therapy.

One patient had a dramatic regression of lymph node metastases in the supraclavicular and axillary regions. However, after 6 months of therapy he died in meningeal relapse, without recurrence of metastases in the lymphatics. Stable disease was seen in 3/12 patients for at least 6-month and 8/12 patients had progressive disease. The treatment was well tolerated without significant side effects during the examination period (Gyergyai et al. 2003).

\section{ANTI-INFLAMMATORY, NEUROGENIC INFLAMMATION INHIBITORY AND ANALGESIC EFFECT OF TT-232}

TT-232 has been found to inhibit both neurogenic and non-neurogenic inflammation. The molecular mechanism of the general anti-inflammatory activity can be linked to the growth inhibition of activated lymphocytes via either the SSTR-dependent cell cycle block or the SSTR-independent rapid cell death and to the inhibition of secretion of certain inflammatory mediator cytokines.

\section{SSTR4 and SSTR1 Play an Important Role in the In vivo Anti-inflammatory Activity of TT-232}

In the rat adjuvant arthritis model, SSTR3 and SSTR4 receptor subtypes are overexpressed in the immune system. In this model, octreotide, which had high affinity for SSTR2 and SSTR5 (Siehler et al. 1998), does not effect the severity of the inflammation (ten Bokum et al. 1999), but the daily administration of TT-232 $(2 \times 100-500 \mu \mathrm{g} / \mathrm{kg}$ i.p. $)$ throughout the experimental period of 18 days dose-dependently inhibits oedema and inflammatory mechanical hyperalgesia (Pinter et al. 2002). Octreotide had also no such effect in mustard oil-induced neurogenic inflammatory models, where TT-232 was proved to be highly effective (Helyes et al. 2001). Therefore, we presume that SSTR4 - and less importantly also SSTR1 - mediated signalling is responsible for the anti-inflammatory action of somatostatin and TT-232. Inhibition of tyrosine kinases by TT-232 (Keri et al. 1993b), is not likely to be a mechanism of its anti-inflammatory and analgesic effect, since a potent tyrosine kinase inhibitor, genistein, failed to influence the stimulated sensory neuropeptide (P-substance, calcitonin gene-related peptide (CGRP)) release (Pinter et al. 2002). On the other hand, blocking the action of G-protein-coupled receptors by pertussis toxin, prevents the inhibition induced by TT-232 on the release of sensory neuropeptides in response to electrical field stimulation of 
sensory fibres in the rat trachea in vitro (Pinter et al. 2002; Helyes et al. 2003).

\section{TT-232 Inhibits the Proliferation of Activated B- and} T-lymphocytes

The possible anti-proliferative effect of TT-232 was assessed on stimulated T- and B-lymphocyte cultures. The rate of proliferation was determined by ${ }^{3} \mathrm{H}$-thymidine incorporation assay. After $48 \mathrm{~h}$ incubation, $\mathrm{IC}_{50}$ values ranged between 10 and $20 \mu \mathrm{g} / \mathrm{ml}$ in different cell cultures. Interestingly for B-lymphocytes the average $\mathrm{IC}_{50}$ value was $13 \mu \mathrm{g} / \mathrm{ml}$, while for T-lymphocytes it was $6.6 \mu \mathrm{g} / \mathrm{ml}$ (unpublished results) (Figs. 2 and 3). This assay did not reveal whether the mechanism of growth inhibition was cell cycle block or apoptosis. However, since cells were incubated continuously with TT-232, SSTR-independent induction is the most likely mechanism. This is further supported by the observation that octreotide, the

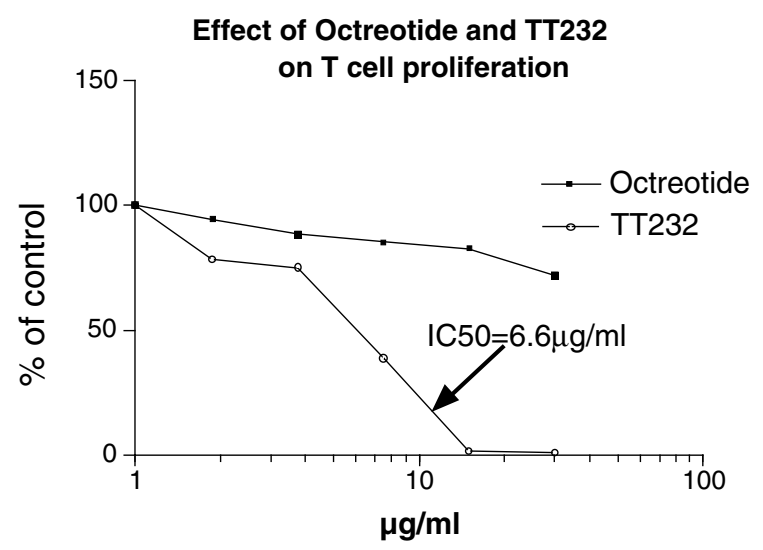

Fig. 2. Effect of octreotide and TT-232 on T-cell proliferation.

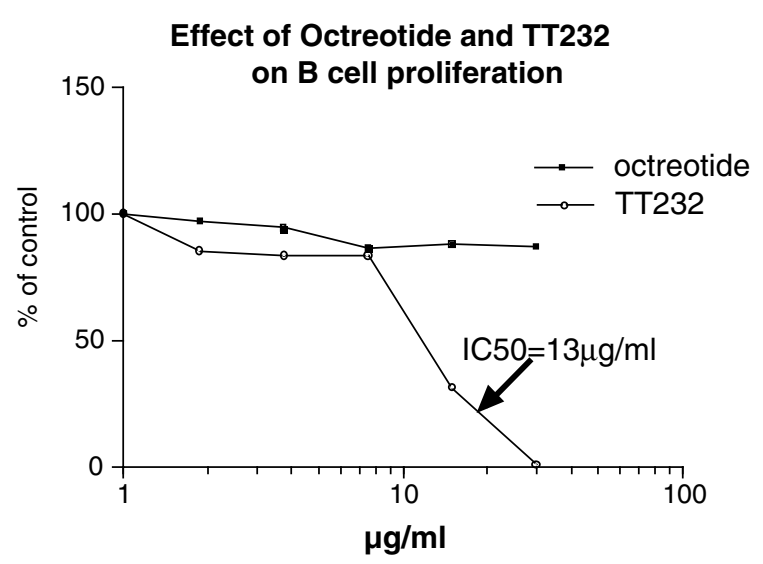

Fig. 3. Effect of octreotide and TT-232 on B-cell proliferation. effective inhibitor of SSTR2, SSTR mainly expressed by human lymphocytes, did not inhibit lymphocyte proliferation.

\section{In vivo Anti-inflammatory, Analgesic and Neurogenic Inflammation Inhibitory Activity of TT-232}

TT-232 is a potent anti-inflammatory and analgesic agent with a broader spectrum than the presently available anti-inflammatory/analgesic agents. In animal models it is effective against neurogenic inflammation and blocks neuropathic hyperalgesia unlike COX-1 or COX-2 inhibitors e.g. diclofenac or meloxicam which are ineffective in these respects. It is about 100 times more potent analgesic than morphine and its efficacy is higher than that of diclofenac. TT-232 is a potent anti-inflammatory agent in a series of inflammatory models, and in addition it inhibits neurogenic inflammation which can not be inhibited by any of the known non-steroidal agents. TT-232 did not produce mucosal ulcerations in the stomach and duodenum of the rat up to 1000-times higher dose range $(0.5-5 \mathrm{mg} / \mathrm{kg}$ i.v.) than its doses which induce analgesic/anti-inflammatory effects (Pinter et al. 2002).

Neurogenic and non-neurogenic components simultaneously take part in most of the inflammatory processes, and neurogenic inflammation plays significant role in the pathogenesis of rheumatoid arthritis, and several other diseases and also in adjuvant arthritis in the rat, and murine delayed-type hypersensitivity reactions. Daily s.c. pre-treatment of rats with doses of TT-232 which inhibited neurogenic inflammation for $6 \pm 16 \mathrm{~h}$ diminished also the development of Freund adjuvant-induced bilateral arthritis. It has been described in several experimental models that somatostatin suppresses a number of immune functions among others the release of proinflammatory cytokines, lymphocyte proliferation, and immunoglobulin production. In the Freund adjuvant arthritis model activation of T-cell subtypes by Mycobacterium crossreacts with articular tissues causing in this way joint destruction and enhancement of local immune responses. The fact that this type of systemic chronic inflammatory response is also inhibited by somatostatin analogue which devoid of endocrine effects opens new horizons for development of broad spectrum anti-inflammatory agents which are effective also against neurogenic inflammation. TT-232 is a promising, effective, stable and selective somatostatin analogue for parenteral 
application. It is proposed as a lead molecule for a new class of anti-inflammatory, analgesic agents.

This favourable scope of action of TT-232 is attributed to a selective action on SSTR1 and SSTR4 somatostatin receptors, while the endocrine effects are mediated by activation of SSTR2, SSTR3 and SSTR5 receptors. Thus based on a series of in vitro and in vivo efficacy experiments we completed the preclinical studies with TT-232 for phase I clinical investigations, and will start the phase $\mathrm{I} / \mathrm{b}$ and phase II clinical studies for burned patients (where strong analgesic and neurogenic inflammation inhibition is required) and rheumatoid arthritis indications. Rheumatoid arthritis affects about $0.5-1 \%$ of the population in the developed world and the strong neurogenic inflammatory part of arthritis cannot be treated with any of the presently used drugs. The therapeutic effect of native somatostatin on rheumatoid arthritis has been proved, but its therapeutic application is limited by the endocrine side effects and by the short plasma half life. Our aim is to develop TT-232 as a broad spectrum analgesic, anti-inflammatory and neurogenic inflammation inhibiting agent for severe conditions in burned patients and rheumatoid arthritis. Additional indications might include asthma, certain kind of allergies and sport accidents where strong analgesic and anti-inflammatory effect has to be quickly achieved via injecting the drug.
Tables II-IV summarises the effect of TT-232 on various neurogenic inflammatory, arthritis and analgesic models.

\section{PRECLINICAL STUDIES}

The active ingredient is synthetised with a patented technology on solid phase (Lifferth et al. 2000). TT-232 has proved a stable molecule, no decomposition was detected in lyophilised form at $25^{\circ} \mathrm{C}$ when protected from light for 3 years The $0.1 \%$ injection solution, kept at $4^{\circ} \mathrm{C}$, was stable for at least 2 years, showing only $1 \%$ decrease in the TT-232 content.

\section{Toxicity Studies}

Toxicology and other safety studies were carried out at the institute for drug research (IDR) in Hungary between 1996 and 1999 in accordance to good laboratory practice (GLP) guidelines. Toxicology, immunogenicity, teratology, mutagenicity and safety pharmacology were performed (Tables V and VI). Overall results of the numerous toxicity studies showed that TT-232 has practically no toxic effects in the clinically relevant dose range. It shows no toxic accumulation, proved not to be an allergen and had no mutagenic effects. The most significant feature is that TT-232 does not affect the function or mor-

Table II. Effect of TT-232 on Various Neurogenic Inflammatory Models

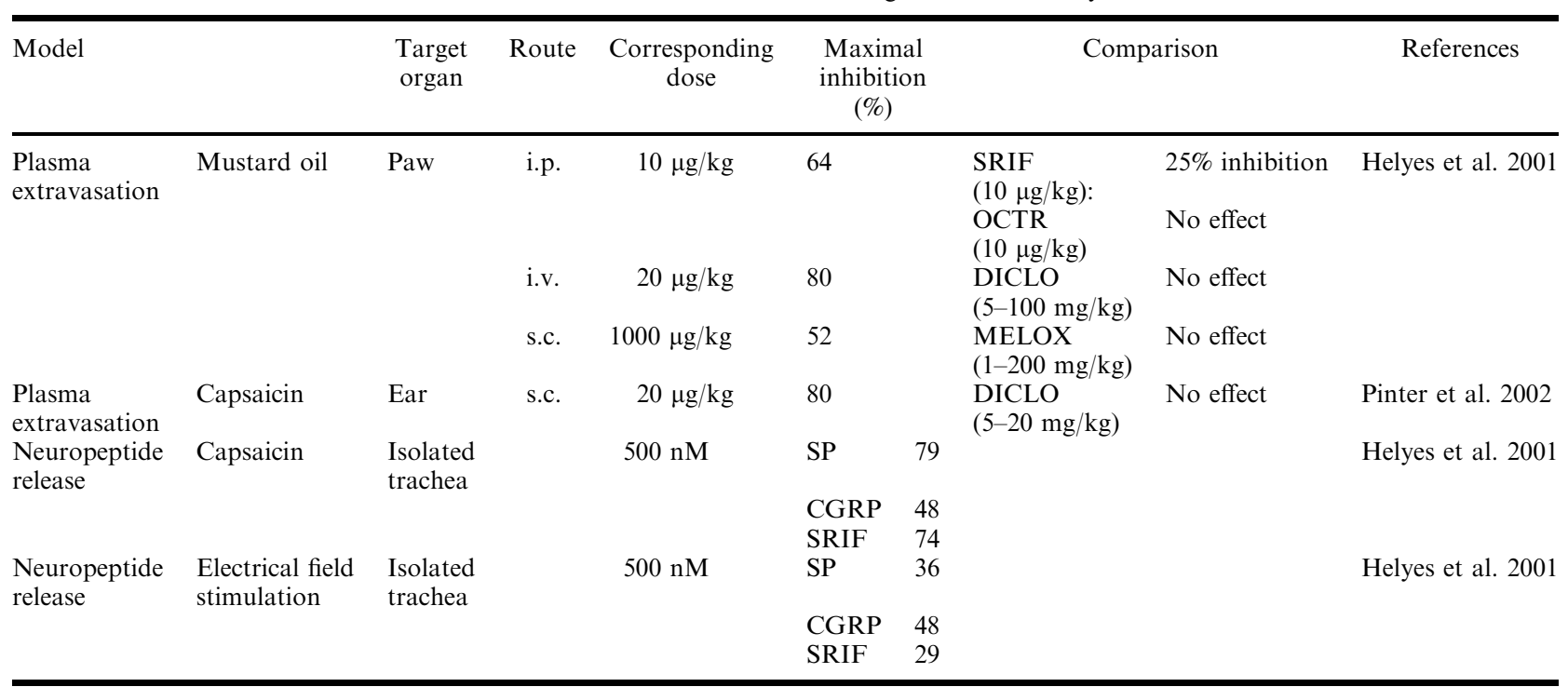

Experiments were carried out mainly in rats,the capsaicin induced plasma extravasation was examined in mice, SRIF = somatostatin; OCTR = octreotide; DICLO = diclofenac; MELOX = meloxicam. 

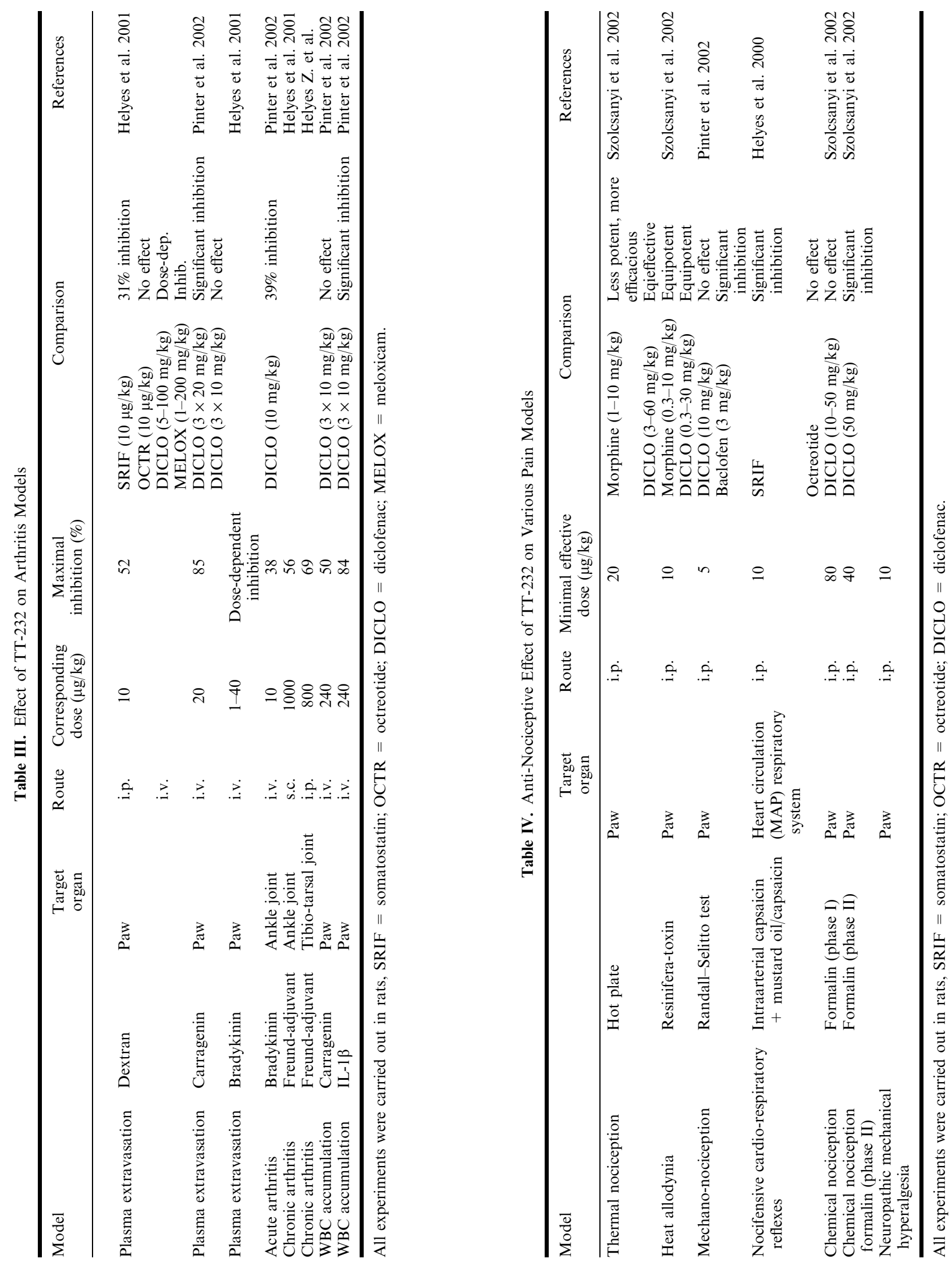
Table V. LD Lo $_{50}$ and ALD Values in Different Species

\begin{tabular}{lcc}
\hline Species & LD $_{50}(\mathrm{mg} / \mathrm{kg})$ & ALD $(\mathrm{mg} / \mathrm{kg})$ \\
\hline Mice & 45.0 & \\
Rat & 37.3 & \\
Rabbits & 20.0 & \\
Rabbits & & 20.0 \\
Dogs & & 20.0 \\
\hline
\end{tabular}

phology of tissues as most cytotoxic agents do (e.g. in haematopoietic and immune-competent tissues and small intestinal mucosa, etc). Minor side effects detected include local irritative effect and systemic blood pressure lowering effect.

\section{Safety Pharmacology}

Safety pharmacology studies were performed in the following models: behavioural studies on mice, potentiation of hexobarbital-Na narcosis on mice, inhibition of electroconvulsive shock on mice, motility study on the rat, effect on the body temperature of the rat, gastrointestinal studies on mice, ulcerogenecity study on the rat, influence of diuresis on the rat, blood circulating studies on anaesthetised rats and phenylquinone writhing test on mice.

No CNS-related toxicity e.g. change in behaviour, motility or temperature was found in the 3 and $10 \mathrm{mg} / \mathrm{kg}$ i.v. dose levels. It has no anti-convulsive, narcoses potentiating, and ulcerogenic activity. TT-232 had slight diuretic effect and mean arterial pressure of anaesthetised rats was dose-dependently decreased at the $10 \mathrm{mg} / \mathrm{kg}$ dose level.

\section{Mutagenicity Studies}

Mutagenicity of TT-232 was evaluated in the Salmonella typhimurium microsome mutation test in the presence and absence of a mammalian metabolic activation system and TT-232 can be considered not mutagenic.

\section{Reproduction Toxicology Studies}

Pilot pre-implantation and teratology studies in rats: female Wistar rats were treated with 1,3 and $10 \mathrm{mg} / \mathrm{kg}$ daily doses of TT-232 on days $1-6$ (preimplantation) and 7-16 (teratology) of pregnancy. The applied doses had no detectable influence on the pre-implantation and intrauterine development of embryos and were not teratogenic.

Pilot pre- and post-natal studies in rats: no effects were seen up to doses of $10 \mathrm{mg} / \mathrm{kg}$ of TT-232 in mothers including duration of pregnancy, delivery process, intra- and extra-uterine mortality rate of still births, gender of the offspring, and post-natal development. No macroscopic changes were detectable at the autopsy of offspring.

Teratology studies of TT-232: The objective of the studies was to assess the effect of TT-232 on the course and outcome of pregnancy. It was intended to provide general information concerning the effects of pre-natal exposure on the pregnant animals and on the developing conceptuses during the organogenesis after intravenous administration of TT-232 at four (rats) and three (rabbits) dose levels. The clinical symptoms, mortality, necropsy findings, body weight gain and reproduction data of the mothers were evaluated. The body weight of the foetuses and weight of placenta were measured, and the external, visceral and skeletal abnormalities of foetuses were recorded and evaluated. Data showed that TT-232 up to $15 \mathrm{mg} / \mathrm{kg} /$ day has not teratological effect in rats and rabbits.

Effect on spermatogenesis in a 28-day study in rats: TT-232 did not cause alterations of sperm parameters including motility, morphology and counts in the doses applied (up to $10 \mathrm{mg} / \mathrm{kg}$ ) confirming no effect

Table VI. Toxicity Studies in Different Species

\begin{tabular}{|c|c|c|c|c|c|c|c|}
\hline Species & $\begin{array}{l}\text { NOAEL } \\
(\mathrm{mg} / \mathrm{kg})\end{array}$ & Low-toxic & $\begin{array}{l}\text { High-toxic } \\
(\mathrm{mg} / \mathrm{kg})\end{array}$ & $\begin{array}{l}\text { Bone } \\
\text { marrow }\end{array}$ & $\begin{array}{l}\text { Kidney } \\
(\mathrm{mg} / \mathrm{kg})\end{array}$ & Liver & Comments \\
\hline Rat 28 days & 1 & $3 \mathrm{mg} / \mathrm{kg}$ & 10 & None & 10 & None & $\begin{array}{l}\text { Renal tubular degeneration } \\
+ \text { local irritation at injection site }\end{array}$ \\
\hline Rabbit 28 days & 0.5 & $2 \mathrm{mg} / \mathrm{kg}$ & 6 & None & 6 & None & $\begin{array}{l}\text { Renal tubular degeneration } \\
+ \text { local irritation at injection site }\end{array}$ \\
\hline Rat 90 days & 2 & n.a. & 6 & None & 6 & None & \\
\hline Dog 90 days & 0.5 & n.a. & 2 & none & 6 & 2 & $\begin{array}{l}\text { Reversible elevation of liver transaminases, } \\
\text { BUN, creatinine in plasma }\end{array}$ \\
\hline
\end{tabular}


of TT-232 to the spermatogenesis in rats after 28 days.

\section{ADME Studies}

In order to study the fate of TT-232 in the living organism, a ${ }^{14} \mathrm{C}$-labelled derivative was synthetised with a very high specific activity $(489.1 \mathrm{kBq} / \mathrm{mg})$ at the Institute of Isotopes, Budapest, Hungary. The site of the labelled ${ }^{14} \mathrm{C}$-atom was the $\alpha$ position of the $\mathrm{D}(-)$ phenylalanine. Both chemical and radiochemical purity were above $95 \%$. On the basis of statistical calculations it was established, that after a single $2 \mathrm{mg} / \mathrm{kg}$ intravenous administration of TT-232 a significant gender-dependent differences in the main characteristic pharmacokinetic parameters $\left(t_{1 / 2}\right.$, AUD, AUD $_{\mathrm{e}}$, MRT and $\mathrm{Cl}_{\text {tot }}$ ) were not found.

\begin{abstract}
Absorption
Absorption of $2 \mathrm{mg} / \mathrm{kg} \quad{ }^{14} \mathrm{C}$-labelled TT-232 administered subcutaneously and intraperitoneal was rapid and significant, resulting in high bioavailability. However, at a $20 \mathrm{mg} / \mathrm{kg}$ subcutaneous and intraperitoneal dose the absorption was rapid but limited. Oral bioavailability is poor. Best, not limited bioavailability can be achieved via intravenous administration where $20 \mathrm{mg} / \mathrm{kg}$ TT-232 results in $30 \mu \mathrm{g} / \mathrm{ml}$ peptide in the circulation for about $2 \mathrm{~h}$. Independently from the administration route (i.v., s.c. or i.p.), the blood concentration were about the half of the corresponding plasma levels indicating a very weak binding of radioactivity to blood cells.
\end{abstract}

\section{Distribution}

Approximately $\quad 60-70 \%$ of ${ }^{14} \mathrm{C}-\mathrm{TT}-232$ was bound to plasma proteins in reversible manner in the in vitro setting. The strong, irreversible binding of radioactivity to plasma proteins may be responsible for extreme long plasma elimination half-life $(>100 \mathrm{~h})$.

Organ levels of total radioactivity increased in time after i.v. administration of $2 \mathrm{mg} / \mathrm{kg}$ TT- 232 . Highest organ levels were found in the liver and gastrointestinal tract $(60 \%)$ within a few hours after administration. High organ levels were found in the kidneys as well, reflecting the prominent role of urinary elimination of radioactivity. Low concentrations in brain (about $0.1 \mu \mathrm{gE} / \mathrm{g}$ ) indicated weak penetration of radioactivity through the blood-brain barrier.

\section{Metabolism}

Ten minutes after administration the main part of radioactivity seems to be TT-232. At $2 \mathrm{~h}$ after intravenous treatment the parent compound could not be detected in plasma. The main detectable component seems to be the free, labelled D-phenylalanine. At 3 and $6 \mathrm{~h}$ after treatment the plasma samples - independently from the administration route - contained radioactivity in protein bound form only.

Unchanged TT-232, D-phenylalanine, one further main metabolite of TT-232 and minor metabolites (that do not bind to proteins) were excreted by urine. The main part of radioactivity excreted with urine was the original compound.

The main radioactive component in bile (independently from time) seemed to be TT-232. Although approximately $50-60 \%$ of the administered dose was excreted by bile mainly during the first $2 \mathrm{~h}$, at later time points, unchanged peptide could not be found either in plasma (as the sign of reabsorption in unchanged form) or in faeces (as sign of elimination). It can be supposed, that the radioactivity had to be decomposed in the intestines by digesting enzymes, and a part of radioactivity reabsorbed and transported via portal vein to liver where further metabolic transformations might also be possible.

\section{Excretion}

The first phase of elimination of total radioactivity was rapid. Most of the radioactivity administrated was excreted in the first $4 \mathrm{~h}$ in bile and 6-12 $\mathrm{h}$ in urine. During the 1-week collection period $30 \%$ of radioactivity was excreted with urine and $10 \%$ in faeces. Most of the missing radioactivity was found in cadaver $(40 \%)$.

The main pathway of elimination is by bile (about $50-60 \%$ of dose administered) within a few hours. The amount of radioactivity excreted in bile got into the intestines and was transformed to fragments. Because of the enterohepatic recirculation most of the radioactivity excreted with the bile does not get into the faeces but gets back to the systemic blood circulation - resulting in relatively high blood and plasma levels after the 1st posttreatment hour.

Elimination of radioactivity from plasma is slow $\left(\mathrm{t}_{1 / 2}\right.$ is approximately $\left.100 \mathrm{~h}\right)$ and an important part of radioactivity remained in the animals. This phenomenon is most probably due to the radioactivity of the ${ }^{14} \mathrm{C}$-labelled $\mathrm{D}(-)$ phenylalanine or its fragments. 


\section{TT-232 ANALOGUES AND FOLLOW-UP MOLECULES (LIPO-AMINO ACIDS, SUGAR-CONTAINING AMINO ACIDS)}

In order to investigate structure - activity relationships we have synthesised a big series of TT-232 analogues, systematically changing various amino acids in the structure, (earlier TT-232 was developed by systematic changes or 'leave out' in a traditional octapeptide somatostatin analogue). A series of these analogues is shown in Table VII. Some of these analogues had comparable anti-proliferative effect as TT-232, but none of them was better, and none of them had better physicochemical or bioavailability parameters. In order to improve bioavailability we have synthesised lipo-amino acid derivatives and sugar-amino acid containing derivatives.

\section{Lipo-Amino Acid Containing TT-232 Analogues}

A lipo-amino acid (LAA) based drug-delivery system was used to try to enhance oral availability of the drug-candidate. The method involves combining the peptide or drug with an LAA moiety (Fig. 4), which acts as a carrier. LAAs combine the properties of amino acids $\left(\mathrm{NH}_{2}\right.$ and $\mathrm{COOH}$ groups) with dose of lipids (hydrophobic side chains) to enhance passive transfer via cellular membranes in a stable and biologically active form (Gibbons et al. 1990; Toth 1994). LAAs are highly versatile molecules, their length and degree of unsaturation, as well as, their stereochemistry can be modified. They can be specifically tailored to transport a wide variety of peptides or poorly absorbed drugs across the barriers that normally inhibit absorption from the gut or into the brain. Furthermore, peptides are released from the LAA conjugate after absorption (i.e. the conjugate becomes the active moiety). Although conjugation of LAAs improves the lipophilicity necessary for crossing biological membranes, it can have an adverse effect on the water solubility. The conjugate has to show a certain degree of water solubility, to allow absorption from the gastrointestinal tract, so liposaccharides (LS) could improve this parameter.

LAA conjugates of TT-232 were synthesised with modifications in the relative position, the number, and the nature of the lipid and/or saccharide moieties (Fig. 4). In vitro results confirmed biological efficacy comparable to the parent compound. ADME studies in $\mathrm{CaCo}-2$ monolayers showed promising permeability coefficient $P_{\text {app }}$ values $\left(P_{\text {app }}=0.86 \times 10^{-6}\right)$ with some conjugate follow-up molecules (Tóth et al.
Table VII. Structure of Traditional TT-232 Analogues

\begin{tabular}{|c|c|}
\hline $\begin{array}{l}\text { TT-232 } \\
\text { (Biostatin) }\end{array}$ & 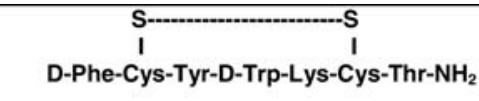 \\
\hline BAH27 & 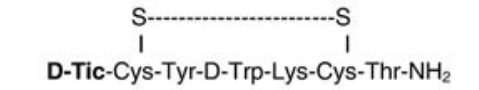 \\
\hline BAH21 & $\begin{array}{c}\text { S- } \\
\text { D- } \beta-N a l \text {-Cys-Tyr-D-Trp-Lys-Cys-Thr-NH }\end{array}$ \\
\hline VZ927B & 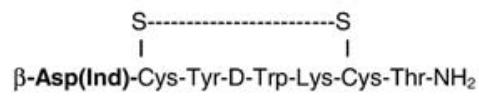 \\
\hline VZ936 & $\begin{array}{c}\text { S-.-S } \\
1 \\
\text { D-Cpa-Cys-Tyr-D-Trp-Lys-Cys-Thr-NH }\end{array}$ \\
\hline VZ1017 & $\begin{array}{c}\text { Sly-Cys-Tyr-D-Trp-Lys-Cys-Thr-NH } \\
\text { G }\end{array}$ \\
\hline VZ1024 & 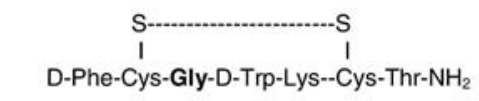 \\
\hline VZ1021 & $\begin{array}{c}\text { S- } \\
\text { I } \\
\text { D-Phe-Cys-Tyr-Gly----Lys--Cys-Thr-NH }\end{array}$ \\
\hline VZ934A & $\begin{array}{c}\text { S-Pys-Tyr-D-Trp-Gly--Cys-Thr-NH } \\
\text { D-Phe-Cys }\end{array}$ \\
\hline VZ1038 & $\begin{array}{c}\text { S-c.--S } \\
\text { I } \\
\text { D-Phe-Cys-Tyr-D-Trp-Lys--Cys-Gly-NH }\end{array}$ \\
\hline BAH39 & D-Phe -Cys-Phe-D-Trp-Lys-Cys-Thr-NH \\
\hline BAH38 & $\begin{array}{c}\text { S-as } \\
1 \\
\text { D-Phe -Cys-Tic-D-Trp-Lys-Cys-Thr-NH }\end{array}$ \\
\hline VZ1038A & $\begin{array}{c}\text { S-.--S } \\
\text { I } \\
\text { D-Phe-Cys-Tyr-D-Pal-Lys--Cys-Gly-NH }\end{array}$ \\
\hline $\mathrm{BAH} 30$ & $\begin{array}{c}\text { S-Phe } \\
1 \\
\text { D-Phs-Tyr-D-Trp-Orn-Cys-Thr-NH }\end{array}$ \\
\hline VZ1026 & 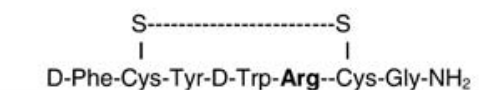 \\
\hline
\end{tabular}

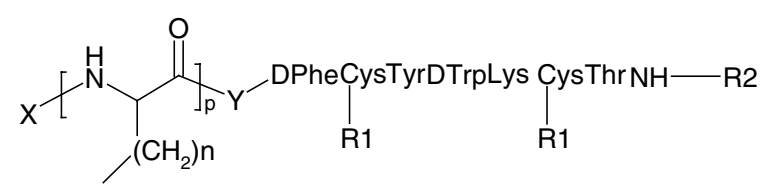

Fig. 4. General formula of lipo-amino acid conjugates. X: H or sugar moiety, Y: None or GlyGly or GABA, R1: disulphide bridge or ACM, R2:H or LAA or sugar moiety. 
1999). Analogues containing only lipo-amino acids had the best activity (in the range of that of TT-232) but solubility and bioavailability decreased even compared to TT-232. A good permeability value could be achieved only if liposaccharide was attached to the molecule, but than the bioactivity decreased. Our conclusion was that although the $\mathrm{N}$ and C-terminal modification of TT-232 with LAA or LS result in amphipathic surfactant like molecules with improved bioavailability, this changes decreased bioactivity of the molecules. To improve physicochemical properties of the parent compound an additional approach was chosen where we incorporated novel kind of sugar moieties into the parent peptide.

\section{Sugar Amino Acid Containing TT-232 Analogues}

Chimeras of the three big classes of biopolymers, i.e. nucleic acids, proteins and carbohydrates, have attracted great interest as both functional, and structural analogues in recent years, also because of their potential application in drug design. Sugar amino acids (SAAs) and their oligomers, which bridge carbohydrates and proteins, have also attracted much interest from the early 1990s (Suhara et al. 1996; Wessel et al. 1996; Lohof et al. 1999; Brittain et al. 2000). SAAs are sugar moieties containing at least one amino- as well as at least one carboxyl-group (Fig. 5). They allow among other modifications the replacement of the naturally occurring, but synthetically difficult to generate, O-/ $\mathrm{N}$-glycosidic bonds by peptidic bonds. This not only increases their enzymatic stability, but facilitates the assembly of large, diverse oligomer carbohydrate or peptidomimetic libraries by solid phase techniques, as well.

SAA containing TT-232 analogues have been shown to possess anti-proliferative and apoptotic activity against both multidrug-resistant and sensitive haepatoma carcinoma cells (Gruner et al. 2001). Four analogues have $\mathrm{IC}_{50}$ values in the low $\mu \mathrm{M}$ range, making them promising leads for chemotherapeutic
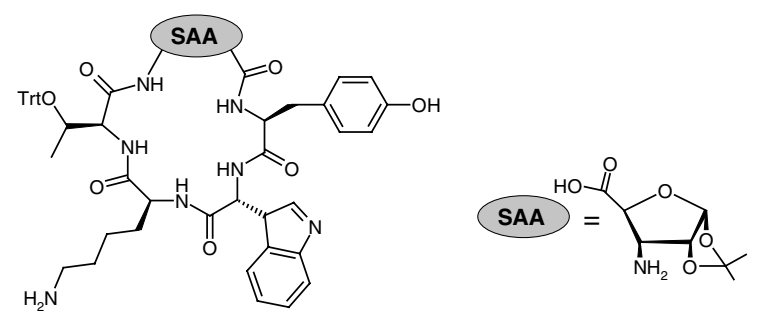

Fig. 5. General formula of sugar amino acid conjugates. drug candidates. A big aromatic residue in the $\mathrm{Thr}^{10}$ position seems to be imperative for high anti-proliferative and apoptotic activity. Replacement of the D-Trp with D-Bta (D-benzothienylalanine) resulted in analogues with even higher biologic efficacy. In view of the non-proteinogenic properties of SAAs, these compounds are very promising follow-up molecules with increased stability and enhanced bioavailability. An international patent has been filed on these compounds in collaboration with Novaspin Biotech GMBH.

\section{FUTURE PERSPECTIVES}

Within 2-year stime, TT-232 is expected to reach proof-of-concept phase III. clinical trials in both oncological and anti-inflammatory indications. During this time developments in topical administration are planned.

One of the key elements of the development process involves research on target theranostics: molecule-targeted diagnostics to predict drug-efficacy and enabling a personalised treatment approach in individual clinical cases.

\section{REFERENCES}

Brittain, D. E. A., Watterson, M. P., Claridge, T. D. W., Smith, M. D. and Fleet, G. W. J.: 2000, J. Chem. Soc. Perkin Trans. 1(21), 3655-3665.

Diaconu, C. C., Szathmari, M., Keri, G. and Venetianer, A.: 1999, Br. J. Cancer. 80(8), 1197-1203.

Gamse, R., Leeman, S. E., Holzer, P. and Lembeck, F.: 1981, Naunyn. Schmiedebergs Arch. Pharmacol. 317(2), 140-148.

Gibbons, W. A., Hughes, R. A., Szeto, A., Charalambous, M., Aulabaugh, A., Mascagni, P. and Toth, I.: 1990, Liebigs Ann. Chem. 12, 1175-1183.

Gruner, S. A., Keri, G., Schwab, R. and Venetianer A. Kessler, H.: 2001, Org. Lett. 3(23), 3723-3725.

Gyergyai, F., Gödény, M., Szüts, T., Kéri, Gy., Sármay, G. and Bodrogi, I.: 2003, European Journal of Cancer Supplements. $1,297-$.

Helyes, Z., Than, M., Oroszi, G., Pinter, E., Nemeth, J., Keri, G. and Szolcsanyi, J.: 2000, Neurosci. Lett. 278(3), 185-188.

Helyes, Z., Pinter, E., Nemeth, J., Keri, G., Than, M., Oroszi, G., Horvath, A. and Szolcsanyi, J.: 2001, Br. J. Pharmacol. 134(7), 1571-1579.

Helyes, Z., Pinter, E., Nemeth, J. and Szolcsányi, J.: 2003, Curr. Med. Chem. - Anti-Inflammatory \& Anti-Allergy Agent. 2, 191-218.

Helyes, Z., Szabo, A., Nemeth, J., Jakab, B., Pinter, E., Banvolgyi, A., Keraskai, L., Keri, G. and Szolcsanyi, J.: 2004, Arthritis Rheum. 50(5), 1677-1685.

Jaspers, H., Horvath, A., Mezo, I., Keri, G. and Van Binst, G.: 1994, Int. J. Peptide Protein Res. 43(3), 271-276. 
Keri, G., Mezo, I., Horvath, A., Vadasz, Z., Balogh, A., Idei, M., Vantus, T., Teplan, I., Mak, M. and Horvath, J.: 1993a, Biochem. Biophys. Res. Commun. 191(2), 681-687.

Keri, G., Mezo, I., Vadasz, Z., Horvath, A., Idei, M., Vantus, T., Balogh, A., Bokonyi, G., Bajor, T., Teplan, I., Tamas, J., Mak, M., Horvath, J. and Csuka, O.: 1993b, Pept. Res. 6(5), 281-288.

Keri, G., Erchegyi, J., Horvath, A., Mezo, I., Idei, M., Vantus, T., Balogh, A., Vadasz, Z., Bokonyi, G., Seprodi, J., Teplan, I., Csuka, O., Tejeda, M., Gaal, D., Szegedi, Z., Szende, B., Roze, C., Kalthoff, H. and Ullrich, A.: 1996, Proc. Natl. Acad. Sci. 93(22), 12513-12518.

Keri, G., Racz, G., Magyar, K., Orfi, L., Schwab, R., Hegymegi, B. B. and Szende, B.: 2004, Ann. N. Y. Acad. Sci. 1010, 109-112.

Lee, J. U., Hosotani, R., Wada, M., Doi, R., Koshiba, T., Fujimoto, K., Miyamoto, Y., Tsuji, S., Nakajima, S., Hirohashi, M., Uehara, T., Arano, Y., Fujii, N. and Imamura, M.: 2002, Eur. J. Cancer. 38(11), 1526-1534.

Lifferth, A., Birr, C., and Braum, G. 2000. Method for producing biostatin (TT-232 triacetate) and analogues thereof. Patent, Internationale Veröffentlichungsnummer, WO 00/11031..

Lohof, E., Burkhart, F., Born, M.A., Planker, E., and Kessler, H. 1999. in: Abel, A. (ed.), Advances in amino acid mimetics and peptidomimetics, Vol. 2. JAI Press Inc. Stanford, Connecticut, pp. 263-292..

Patel, Y. C., Greenwood, M. T., Panetta, R., Demchyshyn, L., Niznik, H. and Srikant, C. B.: 1995, Life Sci. 57(13), 12491265.

Pinter, E., Helyes, Z., Nemeth, J., Porszasz, R., Petho, G., Than, M., Keri, G., Horvath, A., Jakab, B. and Szolcsanyi, J.: 2002, Naunyn Schmiedebergs Arch. Pharmacol. 366(2), 142-150.

Schwab, R. E., Froidevaux, S., Paku, S., Tejeda, M., Szende, B., Pap, A., Beglinger, C., Eberle, A. N. and Keri, G.: 2001, Anticancer Res. 21(1A), 71-75.

Siegrist, W., Solca, F., Stutz, S., Giuffrè, L., Carrel, S., Girard, J. and Eberle, A. N.: 1989, Cancer Res. 49(22), 6352-6358.

Siegrist, W., Stutz, S. and Eberle, A. N.: 1994, Cancer Res. 54(10), 2604-2610.

Siehler, S., Seuwen, K. and Hoyer, D.: 1998, Eur. J. Pharmacol. 348(2-3), 311-320.

Simon, A., Czajlik, A., Perczel, A., Keri, G., Nyikos, L., Emri, Z. and Kardos, J.: 2004, Biochem. Biophys. Res. Commun. 316(4), 1059-1064.
Stetak, A., Lankenau, A., Vantus, T., Csermely, P., Ullrich, A. and Keri, G.: 2001, Biochem. Biophys. Res. Commun. 285(2), 483-488.

Stetak, A., Keri, G. and Ullrich, A.: 2004, 'Pyruvate-Kinase as a Novel Target Molecule'. EP No. 1390525.

Suhara, Y., Hildreth, J. E. K. and Ichikawa, Y.: 1996, Tetrahedron Lett. 37(10), 1575-1578.

Szende, B. and Keri, G.: 2003, Anti-Cancer Drugs. 14(8), 585588.

Szende, B., Horvath, A., Bokonyi, G. and Keri, G.: 2003, Br. J. Cancer. 88(1), 132-136.

Szolcsanyi, J. 2002. Anti-infalmmatory, anti-nociceptive and antihyperalgesic effect of TT-232 in rats and mice. Report, Department of Pharmacology and Pharmacotherapy, Faculty of Medicine, University of Pecs, Hungary.

Tejeda, M., Gaal, D., Schwab, R. E., Pap, A., Szuts, T. and Keri, G.: 2000, Anticancer Res. 20(2A), 1023-1027.

Tejeda, M., Gaal, D., Csuka, O., Ullrich, A., Schwab, R., Pap, A., Horvath, A. and Keri, G.: 2003, Cancer Detect. Prev. 27(2), 155-162.

ten Bokum, A. M., Lichtenauer-Kaligis, E. G., Melief, M. J., Koetsveld, P. M.van, Bruns, C., Hagen, P. M.van, Hofland, L. J., Lamberts, S. W. and Hazenberg, M. P.: 1999, J Endocrinol. 161(1), 167-175.

ten Bokum, A. M., Hofland, L. J. and Hagen, P. M.van: 2000, Eur. Cytokine Netw. 11(2), 161-176.

Tompa, A., Jakab, M. G., Major, J., Idei, M., Bocsi, J., Mihalik, R., Szende, B. and Keri, G.: 2000, Mutat. Res. 465(1-2), 61-68.

Toth, I.: 1994, J.l Drug Target. 2(3), 217-239.

Tóth, I., Malkinson, J. P., Flinn, N., Drouillat, B., Horváth, A., Horváth, J., Érchegyi, J., Idei, M., Venetianer, A., Artursson, P., Lazorova, L., Szende, B. and Kéri, Gy.: 1999, J. Med. Chem. 42(19), 4010-4013.

Tovari, J., Szende, B., Bocsi, J., Falaschi, A., Simoncsits, A., Pongor, S., Erchegyi, J., Stetak, A. and Keri, G.: 1998, Cell. Signal. 10(4), 277-282.

Wessel, H. P., Mitchell, C., Lobato, C. M. and Schmid, G.: 1996, Angew. Chem. 34, 2712-2713.

Zheng, H., Fink, D., Li, H., Jiang, X., Aebi, S., Law, P., Goodman, M. and Howell, S. B.: 1997, Clin. Cancer Res. 3(8), 13231330. 